\title{
A TIME-DEPENDENT THERMODYNAMIC MODEL OF THE BUILD-UP OF SEA-ICE PLATFORMS
}

\author{
By K. SZILDER and E.P. LOZOWSKI
}

(Division of Meteorology, University of Alberta, Edmonton, Alberta T6G 2H4, Canada)

\begin{abstract}
A mathematical model is proposed which gives operational criteria for the construction of artificial, floating ice platforms by water flooding and spraying. The model is based on the one-dimensional heat conduction equation. It gives the change in time of the internal temperature field of the ice layer as it responds to changes in the external conditions. The influence of the atmospheric conditions, including wind speed, air temperature, and cloud cover, on the thermal changes in the ice layer have been considered, both for flooding and for spraying. The importance of the water-delivery conditions, the mass flux of the supplied water, and the degree of droplet cooling during spraying, have also been investigated. The rate of ice growth has been examined for repetitive spraying and flooding, and the quantitative advantage of spraying has been demonstrated.
\end{abstract}

\section{INTRODUCTION}

Floating ice platforms are sometimes constructed to support offshore drilling operations in the High Arctic. Since the rate of natural solidification at the bottom of the ice slows down as the ice thickens, new ice can be formed faster on the ice surface where contact with cold air will accelerate the freezing process. Brine is usually pumped from below the ice, and is delivered to the surface by flooding (Dykins, 1963; Baudais and others, 1974; Masterson and others, 1979; Nakawo, 1980, 1983) or by spraying (Pare and others, 1987; Kemp and others, in press). The latter method is more efficient because the water droplets cool down during their flight through the air. In both methods, the pumped water does not arrive continuously but rather in pulses. Some previous papers have been concerned with the thermodynamics of building ice platforms, e.g. Nakawo (1980), while others have been concerned more with the mechanical properties of the new ice.

The optimization of the construction of ice with the proper mechanical properties is an important problem. For given meteorological conditions and a particular method of water delivery, the optimization of such variables as the single-pulse ice thickness and the curing time need to be examined. In order to produce ice with certain strength characteristics, the curing time should be long enough to allow for a substantial decrease of ice temperature and the required degree of solidification. Nakawo (1980) has proposed a model describing the thermodynamics of artificial ice platforms. The limitations of this model were presented in his paper. He suggested that "Consideration should also be given to the time dependence of surface temperature, since it is probably not a simple function of air temperature and wind speed but a complex one depending on factors such as the thickness of the flooded layer and the temperature profile in the ice."

Our model fulfils these suggestions. It gives a better insight into the thermodynamics of ice platforms, and can be used better to optimize the construction rate. In addition, our model simulates both flooding and spraying.

\section{MODEL}

The thermal changes in the model ice layer are described by the one-dimensional heat-conduction equation:

$$
\frac{\partial T}{\partial t}=\alpha \frac{\partial^{2} T}{\partial z^{2}}
$$

where $\alpha$ is the sea-ice thermal diffusivity, considered to be a function of the ice temperature and its salinity:

$$
\alpha=\frac{k_{\mathrm{i}}}{\rho_{\mathrm{i}} c_{\mathrm{i}}}
$$

where $k_{\mathrm{i}}$ is the thermal conductivity of sea ice (Equation (11)), $\rho_{\mathrm{i}}$ is the sea-ice density, $\rho_{\mathrm{i}}=910 \mathrm{~kg} \mathrm{~m}^{-3}$ (Nakawo, 1980), $c_{\mathrm{i}}$ is the specific heat capacity of sea ice (Equation (3)). A sea-ice layer of $3 \mathrm{~m}$ initial thickness is considered. In order to transform the partial differential heat-conduction equation into a set of ordinary differential equations, the ice volume is divided into 17 layers (Fig. 1). A decreasing ice-layer thickness with height has been assumed because of the increasing temperature gradient towards the surface once growth begins. The uppermost $25 \mathrm{~cm}$ of the ice is divided into seven layers: the first two are $2 \mathrm{~cm}$ thick, the second two $3 \mathrm{~cm}$, and the third three are each $5 \mathrm{~cm}$ thick. The rest of the ice volume is divided into five groups of two layers. The thicknesses of each layer in the pair are 10, 20,30, 40 , and $50 \mathrm{~cm}$, the layer thickness increasing with depth. It is assumed that as the water delivered to the ice surface freezes, a new ice layer, which we shall refer to as the surface layer, is formed. Only this ice layer changes its thickness during the simulation. It increases from zero to a value determined by the total mass per unit area of the delivered water and ice. It is assumed that the unfrozen water forms a separate water layer lying on top of the ice surface.

The upper boundary condition is determined by heat loss to the atmosphere by radiation, convection, and sublimation or evaporation. The latent heat released by the freezing of water is also taken into account. It is assumed that the temperature of the ice in contact with the underlying brine is equal to the freezing temperature of this brine. Sea-water with a salinity of $32 \%$ and a freezing point of $-1.8^{\circ} \mathrm{C}$ are assumed.

The initial distribution of temperature in the ice is calculated assuming a steady state and neglecting any latent heat of freezing. This means that any previous flooding is assumed to have happened sufficiently long ago to allow the system to reach a steady state. The heat loss to the atmosphere from the ice surface, and the equilibrium freezing point at the bottom of the ice layer determine this initial distribution of temperature within the ice. It should be noted that because the sea-ice thermal conductivity is itself a function of temperature, the initial temperature distribution is not linear. This non-linearity is significant, 
AIR

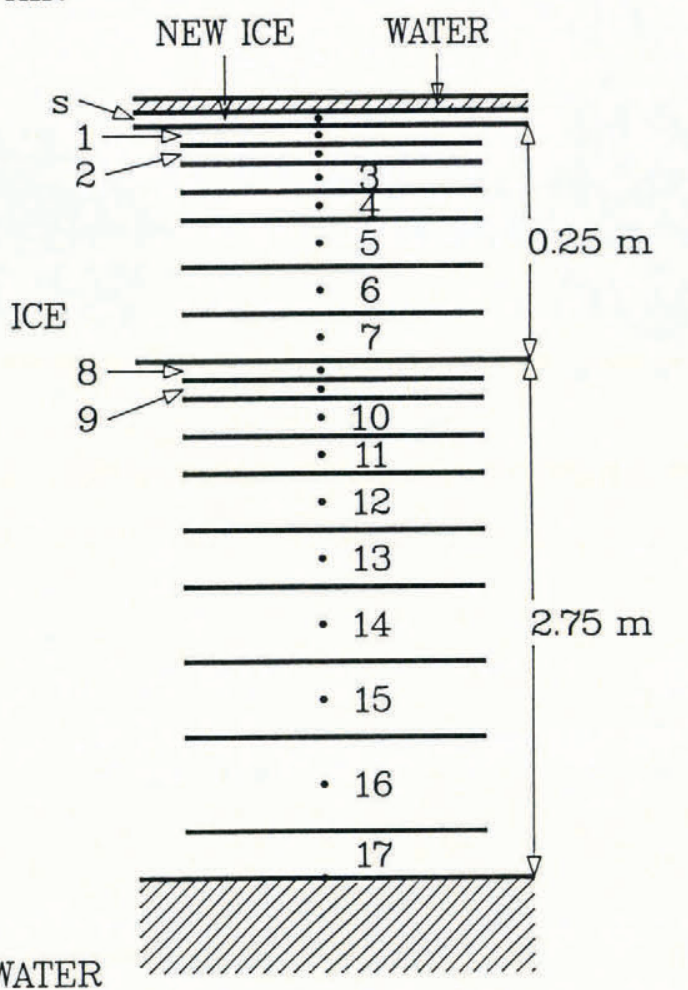

WATER

Fig. 1. Division of the initial sea-ice foundation, of thickness $3 \mathrm{~m}$, into 17 layers. The vertical scale for the upper layers (layers $1-7$, total thickness $0.25 \mathrm{~m}$ ) and the lower layers (layers 8-17, total thickness $2.75 \mathrm{~m}$ ) differs by a factor of 5. A new ice layer forms as the delivered water freezes. A layer of liquid water may exist on the ice surface.

however, only for regions with comparatively high ice temperatures.

Considering the different physical processes which occur at the ice surface, one may divide the entire period of flooding or spraying into three intervals. During the first, the new ice layer starts to grow, and its temperature increases rapidly, reaching the melting point after a short period of time. Changes of the ice-surface temperature are determined by the non-stationary heat balance (Equation (2)). For this first interval, the rate of ice growth is equal to the rate of water delivery, since all the delivered water freezes. This interval is quite short, because the amount of latent heat which must be liberated to freeze all the delivered water is large in comparison with the energy which the water loses by conduction to the underlying ice, or by radiation and convection to the atmosphere.

During the second interval, a water layer exists on the ice surface. It is assumed that the interfacial temperature between this water layer and the ice is constant and equal to $-3^{\circ} \mathrm{C}$. This assumption is made as a thermodynamical convenience to avoid having to deal with physical complexities associated with a detailed consideration of salt rejection and brine-pocket formation. The heat-balance equation determines the rate of ice growth in this stage. When all the water has frozen, the third interval begins. Here, the surface-ice temperature is determined by Equation (2), and its thickness remains constant.

Let us consider the changes of the ice surface-layer temperature. It is determined by the non-stationary heatbalance equation:

$$
c_{\mathrm{i}} \rho_{\mathrm{i}} h_{\mathrm{s}} \frac{\mathrm{d} T_{\mathrm{S}}}{\mathrm{d} t}=Q_{\mathrm{R}}+Q_{\mathrm{S}}+Q_{\mathrm{H}}+Q_{\mathrm{C}}+Q_{\mathrm{F}}
$$

where $Q_{\mathrm{R}}$ is the net long-wave radiation flux (short-wave radiation is ignored), $Q_{\mathrm{S}}$ is the heat flux due to sublimation, $Q_{\mathrm{H}}$ is the sensible heat flux between the icesurface layer and the air, $Q_{\mathrm{C}}$ is the heat flux due to conduction into the ice, $Q_{\mathrm{F}}$ is the latent heat flux released as the brine freezes and its temperature drops to the assumed surface temperature, $h_{\mathrm{S}}$ is the ice surface-layer thickness, and $T_{\mathrm{S}}$ is the ice-surface temperature.

If the ice-surface temperature lies initially below $-3^{\circ} \mathrm{C}$, and water of temperature $T_{\mathrm{w}}=-1.8{ }^{\circ} \mathrm{C}$, and salinity $32 \%$, is delivered to the surface, the water freezes and at first its temperature drops to the surface temperature of the ice. This means that one must consider not only the latent heat of freezing but also the heat flux which is liberated as the temperature of the newly frozen ice begins to fall. While we recognize that the processes of freezing and cooling of the newly formed ice are not physically separable, we prefer to treat them as if they were, as will be seen below.

Our convention is that when heat is added to the surface layer the heat flux is positive, and when heat is lost by the surface layer the heat flux is negative. Equation (2) is valid only when the ice-surface temperature, $T_{\mathrm{S}}$ is less than the assumed freezing temperature $T_{\mathrm{f}}=-3^{\circ} \mathrm{C}$. If there is not enough heat exchange to freeze all of the supplied water, we have assumed the existence of a water layer on the ice surface. While the water layer exists, which may happen both during and after flooding or spraying, the ice-surface temperature $T_{\mathrm{S}}$ is assumed to be the freezing temperature $T_{\mathrm{f}}$. The process of sea-water solidification and its influence on the thermal properties of both phases and the freezing point is fairly complex. We have tried to keep our model as simple as possible. Consequently, several simplifying assumptions have been made.

In this model, for example, we have replaced the continuous process of latent heat release as brine cools and freezes by a discontinuous one analogous to that for pure water. As an attempt to take into account enrichment of the brine as the ice freezes, we assume that the latent and specific heats which would be given up by the real system in cooling, from $-1.8^{\circ}$ to $-3^{\circ} \mathrm{C}$, are released as a fixed "latent heat", at $-3^{\circ} \mathrm{C}$. Subsequent to this we refer to the system as "frozen", although we recognize that it is not entirely frozen and represents the further release of latent and specific heats as the spongy ice continues to cool, in terms of a specific heat capacity which varies with temperature.

It has been assumed that the specific heat capacity of sea ice as a function of temperature below $-3^{\circ} \mathrm{C}$ is given by the empirical formula (Yen, 1981):

$$
c_{\mathrm{i}}=2.11+0.0075 T_{\mathrm{i}}+18022 \frac{\sigma_{\mathrm{i}}}{T_{\mathrm{i}}{ }^{2}} \mathrm{~kJ} \mathrm{~kg}^{-1} \mathrm{~K}^{-1} .
$$

The ice temperature $T_{\mathrm{i}}$ is expressed here in deg. The salinity of the sea ice $\sigma_{i}$ (in grams of salt per gram of sea ice) is assumed to have the value 20\%o (Nakawo, 1980).

Sea ice has no fixed temperature for phase transition. However, it has been assumed, as stated above, that isothermal freezing of sea ice occurs at $-3^{\circ} \mathrm{C}$. The value of the latent heat of fusion has been found by integrating Equation (3) from $-1.8^{\circ} \mathrm{C}$, the equilibrium freezing temperature of the brine, to the temperature, $T$ :

$$
\ell_{\mathrm{f}}(T)=333 \times T-114.1 \sigma_{\mathrm{i}}+18022 \frac{\sigma_{\mathrm{i}}}{T} \mathrm{~kJ} \mathrm{~kg}^{-1} .
$$

Assuming $T=-3{ }^{\circ} \mathrm{C}$ and $\sigma_{\mathrm{i}}=20 \%$, the value of the latent heat of fusion is $\ell_{f}=217 \mathrm{~kJ} \mathrm{~kg}^{-1}$. This means that in the model we assume that sea-water "freezes" at $-3^{\circ} \mathrm{C}$, releasing a latent heat $\ell_{f}=217 \mathrm{~kJ} \mathrm{~kg}^{-1}$. As the ice continues to cool, additional latent heat is then released, but this is now expressed in terms of the ice specific heat capacity, which varies with temperature according to Equation (3).

Let us now consider all the heat fluxes in Equation (2). The heat flux due to radiation $Q_{\mathrm{R}}$ has been calculated assuming that short-wave radiation is negligible. This is reasonable since ice-platform construction is usually carried out in the High Arctic winter when there is little or no sunshine at all.

Most relations used for calculation of net long-wave 
radiation, e.g. Sellers (1965), Budyko (1974), are valid when the Earth's surface temperature is close to that of the lower layer of air. However, in our model the surface temperature can differ substantially from the air temperature. Consequently, the long-wave downward and upward radiation components have been considered separately. The simple parameterization of the downward flux under clearsky conditions, suggested by Idso and Jackson (1969), is used:

$$
Q_{\mathrm{RD}}=\sigma T_{\mathrm{a}}{ }^{4}\left(1-0.261 \exp \left(-7.77 \times 10^{-4}\left(T_{\mathrm{a}}-273\right)^{2}\right)\right)
$$

where $Q_{\mathrm{RD}}, \sigma$, and $T_{\mathrm{a}}$ are, respectively, the long-wave atmospheric downward radiation flux, the Stefan-Boltzman constant, and the screen-level Kelvin air temperature.

The upward flux of long-wave radiation is given by:

$$
Q_{\mathrm{RU}}=\varepsilon \sigma T_{\mathrm{S}}^{4}
$$

where $\varepsilon$ is the ice emissivity. Values of this parameter suggested by different authors differ substantially. Eckert and Drake (1972) claimed 0.966 for smooth ice and for rough ice 0.985 . Lunardini (1981) gave two values, 0.63 and 0.9 , without specification. Sellers (1965) proposed 0.96 , and Gebhart (1971) specified a range $0.887-0.97$ for different kinds of ice. This discrepancy is presumably caused by different ice structures, roughness, and temperature. It has been assumed that $\varepsilon=0.95$ in the present calculations.

In contrast to $Q_{\mathrm{RU}}, Q_{\mathrm{RD}}$ is affected by the cloud cover. The effect of cloudiness on the net long-wave radiation could be accounted for by an equation of the form:

$$
Q_{\mathrm{R}}=Q_{\mathrm{RD}}\left(1+c n^{a}\right)-Q_{\mathrm{RU}}
$$

where $Q_{\mathrm{R}}$ is the net long-wave radiation under cloudy skies, $n$ is the cloudiness expressed as a fraction, and $c$ and $a$ are coefficients. The constant $c$ is a function of cloud height and cloud type, since the higher and thinner the clouds, the less they will contribute to the downward radiation reaching the ground. Values of the coefficient $c$ for various sky conditions, assuming $a=2$, have been presented by Brutsaert (1982). The average value of $c$ is 0.22 . Serreze and Bradley (1987) performed measurement of $c$ in summer in the High Arctic. Their average value can be estimated as about 0.19 . Because of the uncertainty of the frequency of differing cloud types under the situations prevailing when sea-ice platforms are constructed, we have simply assumed an "average" $c=0.20$.

The latent heat of sublimation of water vapour from the surface may be written:

$$
Q_{\mathrm{S}}=B \rho_{\mathrm{a}} \ell_{\mathrm{s}} \frac{\varepsilon}{p} U_{\mathrm{a}}\left(f e_{\mathrm{a}}-e_{\mathrm{S}}\right)
$$

where $B$ is the eddy-transfer coefficient having a value $4.5 \times 10^{-3}$ (Nakawo, 1980), $\rho_{a}$ is the air density $\left(\rho_{\mathrm{a}}=1.3 \mathrm{~kg} \mathrm{~m}^{-3}\right), \quad \ell_{\mathrm{s}}$ is the specific latent heat of sublimation $\left(\ell_{S}=2840 \mathrm{~kJ} \mathrm{~kg}^{-1}\right), \quad \varepsilon$ is the ratio of the molecular weights of water vapour and dry air $(\varepsilon=0.622)$, $p$ is the air pressure, $U_{\mathrm{a}}$ is the air velocity at the screen level, $e_{\mathrm{a}}, e_{\mathrm{s}}$ are respectively, the saturation vapour pressure at $T_{\mathrm{a}}$ and $T_{\mathrm{s}}$. Values have been calculated using Lowe's (1977) polynomial approximation. No account has been taken of the influence of salinity on vapour pressure. $f$ is the relative humidity of the air. It has been assumed that $f=90 \%$ in our model, although actual measurements could be used if they were available for a particular construction project.

The sensible heat flux is given by:

$$
Q_{\mathrm{H}}=\beta \rho_{\mathrm{a}} c_{\mathrm{p}} U_{\mathrm{a}}\left(T_{\mathrm{a}}-T_{\mathrm{s}}\right)
$$

where $c_{\mathrm{p}}$ is the specific heat capacity at constant pressure of dry air.

The heat flux due to conduction between the ice-surface layer and the ice layer under it may be approximated by:

$$
Q_{\mathrm{C}}=-k_{\mathrm{i}} \frac{T_{\mathrm{S}}-T_{1}}{0.5\left(h_{\mathrm{S}}+h_{1}\right)}
$$

where $k_{\mathrm{i}}$ is the thermal conductivity of the ice, $T_{1}$ is the temperature of the uppermost layer prior to flooding, and $0.5\left(h_{\mathrm{s}}+h_{1}\right)$ is the distance between the ice-layer centers. The thermal conductivity of sea ice depends strongly on temperature and salinity. A relation presented by Yen (1981) has been adopted in our model. Assuming a thermal conductivity of fresh-water ice of $2.0 \mathrm{~W} \mathrm{~m}^{-1} \mathrm{~K}^{-1}$ and an ice density of $910 \mathrm{~kg} \mathrm{~m}^{-3}$, we obtain:

$$
k_{\mathrm{i}}=2.0+81.15 \frac{\sigma_{\mathrm{i}}}{T_{\mathrm{i}}} \mathrm{W} \mathrm{m}^{-1} \mathrm{~K}^{-1}
$$

where the ice temperature is expressed here in deg. The calculations have been performed assuming $\sigma_{i}=20 \%$ throughout.

The brine may be supplied to the ice surface by flooding or by spraying. When the brine is flooded, the temperature of the brine delivered to the ice surface is assumed equal to the temperature of the brine taken from below the ice, i.e. $T_{\mathrm{w}}=-1.8^{\circ} \mathrm{C}$ for $\sigma=32 \%$.

When the brine is sprayed in cold air, the droplets will cool and part of them may freeze. The heat exchange is determined not only by the atmospheric conditions (Zarling, 1980 ) but also by the method of spraying. Such factors as pump power, nozzle type, angular sweeping velocity, angle of projection, and the addition of surfactants to the brine intake, play essential roles in the cooling rate (Pare and others, 1987). In the present paper, no attempt is made to model these processes in detail. Rather, we assume a certain heat loss from the droplets during their flight. This hea loss is expressed non-dimensionally using a normalization constant equal to the heat which would be lost by drops which cool and partly freeze, going from $-1.8^{\circ}$ to $-3.0^{\circ} \mathrm{C}$, and releasing in the process $217 \mathrm{~kJ} \mathrm{~kg}^{-1}$. The ratio of the heat actually lost by the droplets to this normalization constant is called the "spray heat-loss factor" $C$. Since "complete" freezing of the drops would release $424 \mathrm{~kJ} \mathrm{~kg}^{-1}$ (the heat released when cooling and freezing to a final temperature of $-40^{\circ} \mathrm{C}$ ), the value of $C$ may range from 0 to about 2. $C=0$ corresponds to flooding. $C=2$ would likely yield a mass of ice pellets with poor cohesive properties and low strength. Consequently, in our present discussions, we restrict the range of $C$ from 0 to 1 .

In order to consider the last term in Equation (2), $Q_{\mathrm{F}}$, we refer to the previously described time intervals when, sequentially, the delivered water freezes instantaneously, a water layer exists on the ice surface, and the newly frozen ice cools down. We distinguish between flooding and spraying for the first two intervals. Thus:

All the flooded brine freezes during the first period.

$$
Q_{\mathrm{F}}=m_{\mathrm{p}}{ }^{\mathrm{f}_{\mathrm{f}}}\left(T_{\mathrm{s}}\right)
$$

where $m_{\mathrm{p}}$ is the mass flux of water delivered to the surface, and $\ell_{\mathrm{f}}\left(T_{\mathrm{s}}\right)$ is the sea-water latent heat of fusion calculated for the ice-surface temperature $T_{\mathrm{s}}$, using Equation (4). This latent heat includes both phase-change and sensible-heat effects. Its use does not imply complete solidification despite our use of the term "freezing". Rather, it means that the ice/water mixture has cooled from $-1.8^{\circ}$ to $T_{\mathrm{S}}{ }^{\circ} \mathrm{C}$.

When water is delivered by spraying, the heat which is exchanged over the droplets' motion in the cold air must be excluded from $Q_{\mathrm{F}}$. Consequently:

$$
Q_{\mathrm{F}}=m_{\mathrm{p}}\left(\ell_{\mathrm{f}}\left(T_{\mathrm{S}}\right)-C \ell_{\mathrm{f}}\left(T_{\mathrm{f}}\right)\right) .
$$

If there were no heat exchange during the water spraying, the spray heat-loss factor, $C$, would be zero and the second term in Equation (12b) would disappear. On the other hand, if $C=1$, heat is still liberated as the temperature of the newly deposited ice falls to the surface temperature $T_{\mathrm{S}}$. This heat is now proportional to $\ell_{\mathrm{f}}\left(T_{\mathrm{s}}\right)-\ell_{\mathrm{f}}\left(T_{\mathrm{f}}\right)$. The quantity $\ell_{\mathrm{f}}\left(T_{\mathrm{f}}\right)$ is the latent heat of fusion for $-3 \mathrm{C}\left(217 \mathrm{~kJ} \mathrm{~kg}^{-1}\right)$, which, by our assumption, corresponds to the maximum heat exchange between the falling droplets and the cold air.

During the first time period, the growth rate of the ice surface-layer mass, $M_{\mathrm{S}}$, is determined by the total mass flux delivered to the surface: 


$$
\frac{\mathrm{d} M_{\mathrm{S}}}{\mathrm{d} t}=m_{\mathrm{p}}
$$

Equation (13) is valid for both flooding and spraying. It is assumed that the initial mass of the surface layer is zero, i.e. $M_{\mathrm{S}}(0)=0$. The change of the layer thickness is calculated assuming an ice density, $\rho_{i}=910 \mathrm{~kg} \mathrm{~m}^{-3}$.

The first time interval may not last very long if a substantial amount of water is delivered to the surface. During water delivery, the surface temperature of the ice increases and may reach the freezing point, $T_{\mathrm{f}}=-3^{\circ} \mathrm{C}$. At this moment the second interval begins. Now the rate at which heat is taken from the delivered water is not sufficient to allow instantaneous freezing. (The reader should recall that here we use the term "freezing" to describe the process whereby the brine cools and freezes in part until it reaches a final temperature of $-3^{\circ} \mathrm{C}$.) A water layer then starts to develop. It is now assumed that the surface-ice layer is isothermal at $T_{\mathrm{f}}=-3^{\circ} \mathrm{C}$. Consequently, the heatbalance equation, as given in Equation (2), is no longer valid. Rather, it should have the following form:

$$
Q_{\mathrm{R}}+Q_{\mathrm{E}}+Q_{\mathrm{H}}+Q_{\mathrm{C}}+m_{\mathrm{f} \ell_{\mathrm{f}}}\left(T_{\mathrm{f}}\right)=0
$$

where $m_{\mathrm{f}}$ now gives the rate of freezing of the surface brine. It should be noticed that the heat flux due to evaporation $Q_{\mathrm{E}}$ is used at this point instead of the heat flux due to sublimation $Q_{\mathrm{S}}$. These terms have a similar form (Equation (8)), but instead of the specific heat of sublimation $\ell_{s}$ the specific heat of evaporation $\ell_{e}$ is used $\left(l_{\mathrm{e}}=2500 \mathrm{~kJ} \mathrm{~kg}^{-1}\right)$ and the relative humidity of the air $f$ is assumed to be $100 \%$. The three remaining heat-flux terms, $Q_{\mathrm{R}}, Q_{\mathrm{H}}$, and $Q_{\mathrm{C}}$, are calculated using, respectively, Equations (7), (9), and (10), assuming that the emissivity of the surface water, $\varepsilon=0.95$ (Lunardini, 1981).

During this stage, the calculations of the heat fluxes are based on a surface temperature, $T_{\mathrm{f}}=-3^{\circ} \mathrm{C}$, which is an attempt to simulate the effect of enrichment and cooling of the brine as the ice begins to freeze, even though the temperature of the delivered water is $T_{\mathrm{W}}=-1.8^{\circ} \mathrm{C}$. Moreover, we assume that the ice accumulates at the bottom of the water layer in the model. In reality, especially when the mass of delivered water is substantial, ice may also grow at the point of contact with the cold air. If this ice layer covering the water is thick enough, its conductive-heat resistance may significantly alter the surface temperature, thereby changing the heat fluxes exchanged with the atmosphere. This means that, when there is a substantial rate of water delivery, the model may have to be modified in order to yield reliable results.

When water is flooded or sprayed, Equation (14) gives the amount of water which "freezes" at the surface (i.e. reaches a temperature of $-3^{\circ} \mathrm{C}$ ). In addition, when water is sprayed, a proportion of the falling droplets will "freeze". Consequently, the growth rate of the ice surface-layer mass $M_{\mathrm{S}}$ per unit surface area, may be expressed by:

$$
\frac{\mathrm{d} M_{\mathrm{S}}}{\mathrm{d} t}=m_{\mathrm{f}}+C m_{\mathrm{p}}
$$

where $m_{\mathrm{f}}$ is calculated using Equation (14) for flooding and spraying, and $C$ is the spray heat-loss factor.

The mass of unfrozen brine on the ice surface $M_{\mathrm{w}}$ per unit surface area is a function of the difference between the water flux which is delivered to the surface and the water flux which "freezes":

$$
\frac{\mathrm{d} M_{\mathrm{w}}}{\mathrm{d} t}=m_{\mathrm{p}}-\frac{\mathrm{d} M_{\mathrm{S}}}{\mathrm{d} t} .
$$

The initial brine mass is taken to be zero.

When all water at the surface has "frozen" (i.e. converted to spongy brine ice at $-3^{\circ} \mathrm{C}$ ), the third period begins. The latent heat from $Q_{\mathrm{F}}$ is then set to zero, and Equation (2) allows for the ice surface-temperature calculations. A surface water layer does not exist and the ice-surface layer is assumed to have constant thickness. This third period continues until a new pulse of brine arrives.
The effects of the thermal processes at the ice surface propagate downwards by conduction. The rate of change of the ice-layer temperature, $T_{j}$, is determined by the net heat flux:

$$
\begin{array}{r}
c_{\mathrm{i}} \rho_{\mathrm{i}} h_{j} \frac{\mathrm{d} T_{j}}{\mathrm{~d} t}=k_{\mathrm{i}} \frac{T_{j-1}-T_{j}}{H_{j-1, j}}-k_{\mathrm{i}} \frac{T_{j}-T_{j+1}}{H_{j, j+1}} \\
j=1,2, \ldots, 16
\end{array}
$$

where $c_{\mathrm{i}}$ and $k_{\mathrm{i}}$ are functions of the ice temperature and salinity given by Equations (3) and (11), respectively, $h_{j}$ is the $j$ th ice-layer thickness, and $H_{j-1, j}$ is the distance between the centers of the $j-1$ and $j$ ice layers. The ice division into layers, and the boundary and initial conditions, were described at the beginning of this section.

\section{RESULTS}

The set of ordinary differential equations which constitute the model has been solved using the Advanced Continuous Simulation Language (Mitchell and Gauthier, 1981). A fourth-order Runge-Kutta integration algorithm is used. The time step in any particular case is a compromise between solution accuracy and cost of running the program. Typical values have ranged between 5 and $10 \mathrm{~s}$.

\section{Building an ice platform by flooding}

In this section, the simulation results of a single flooding of the ice platform with sea-water are presented. Later, repetitive flooding is considered. The initial distribution of the ice temperature is based on the assumption that any previous flooding occurred sufficiently long ago to have no influence on the temperature distribution Consequently, initially the system is in a steady state. The surface temperature is determined by an equilibrium among the radiative, sublimative, convective, and conductive heat fluxes. The temperature at the bottom of the $3 \mathrm{~m}$ thick ice layer is assumed to be the sea-water temperature, $T_{\mathrm{w}}=-1.8^{\circ} \mathrm{C}$. The conductive heat flux inside the ice layer is constant. The distribution of the temperature with depth is not linear because the ice conductivity is a function of temperature according to Equation (11). However, close to the ice surface, the temperature profile is almost linear (Fig. 2) because the ice conductivity is not very sensitive to changes in temperature when the temperature is low. If the sea-surface temperature is closer to the freezing point, the conductivity is more sensitive to temperature changes. Consequently, close to the bottom of the ice, the temperature distribution is non-linear.

The results presented in Figures 2, 3, 4, 5, and 6 have been computed for the following values of the parameters:

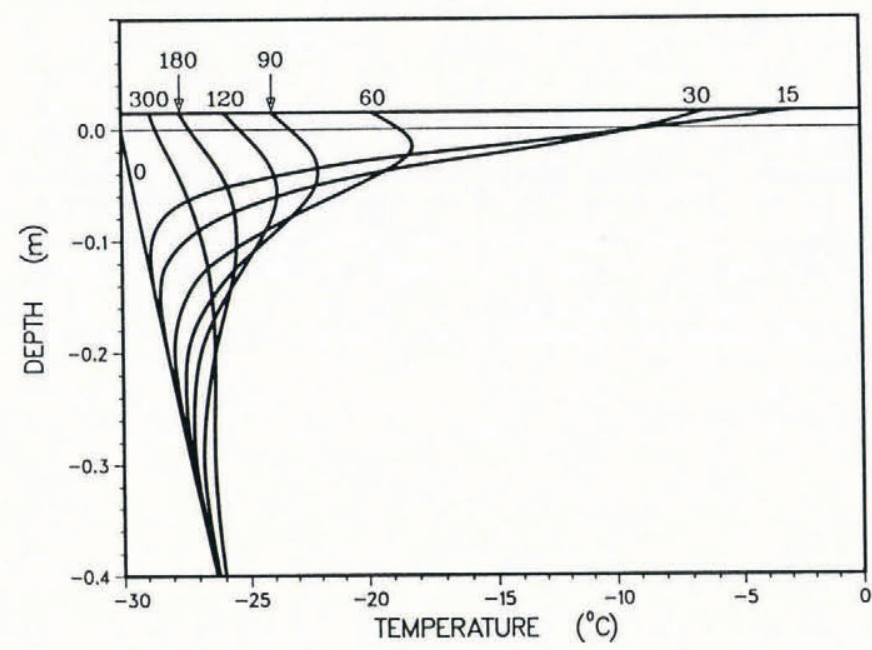

Fig. 2. Temperature distributions in the ice. Time is given in minutes after the beginning of flooding. The old and new ice surfaces are plotted as light and heavy lines, respectively. Air temperature $-30^{\circ} \mathrm{C}$, wind speed $4 \mathrm{~m} \mathrm{~s}^{-1}$, cloudless skies, and a new ice build-up of $15 \mathrm{~mm}$. 
air temperature $T_{\mathrm{a}}=-30^{\circ} \mathrm{C}$, wind speed $U_{\mathrm{a}}=4 \mathrm{~m} \mathrm{~s}^{-1}$, and a clear sky $n=0$. The duration of a single flooding event is $15 \mathrm{~min}$ and, during this time interval, water is assumed to be supplied continuously and uniformly to the ice surface. Once all the water has frozen, there is a $15 \mathrm{~mm}$ build-up of new ice. These assumed values are typical for the construction of artificial ice platforms (Nakawo, 1980).

The water supply starts at the initial moment of the simulation. For an initial period of time, all the delivered water "freezes" instantaneously, because the low ice-surface temperature allows for sufficient heat exchange with the underlying surface for this to occur. The ice surface-layer temperature increases rapidly but its rate of change decreases with time. This occurs because an increasing surface temperature leads to higher heat losses to the underlying ice by conduction, and to the atmosphere by radiation and convection (Fig. 4). The ice surface-layer temperature eventually reaches the melting temperature $T_{\mathrm{f}}=$ $-3^{\circ} \mathrm{C}$ after $8.5 \mathrm{~min}$ (Fig. 3). This happens because the flux of the latent heat of freezing is too big to be in balance with the conductive-heat flux and the heat fluxes exchanged with the atmosphere (Fig. 4). Once the ice-surface temperature reaches $T_{\mathrm{f}}$, an untrapped brine layer is assumed to appear on the ice surface. Now, only part of delivered water "freezes" instantaneously. This abrupt change in the freezing mass flux is associated with a rapid decrease of the freezing heat flux (Fig. 4).

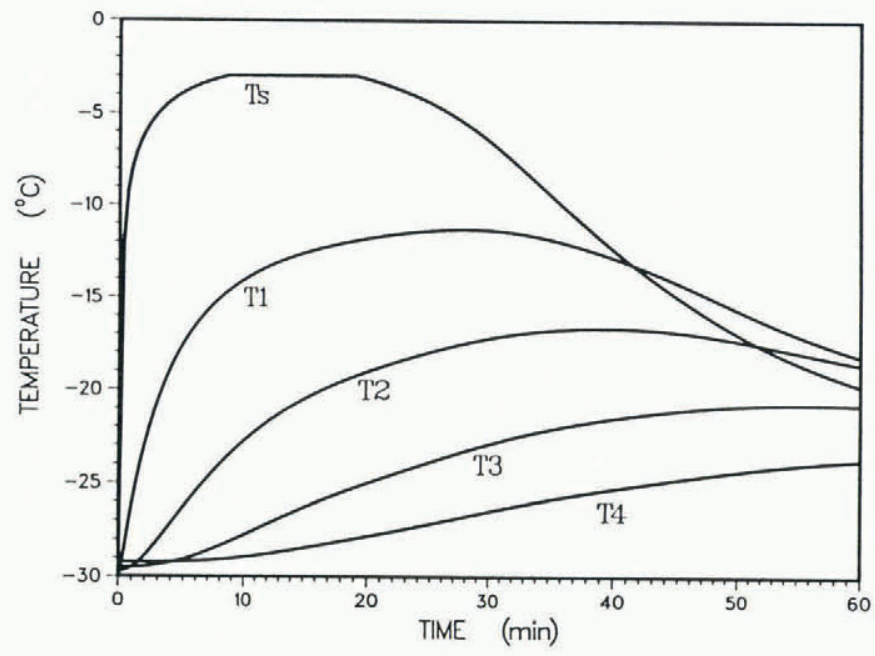

Fig. 3. Temperature of the five uppermost ice lavers as a function of time. The parameters are the same as in Figure 2. $T_{s}$ is the surface ice-layer temperature, and $T_{1}$. $T_{2}, T_{3}$, and $T_{4}$ are temperatures of the four underlying ice layers of total thickness $10 \mathrm{~cm}$.

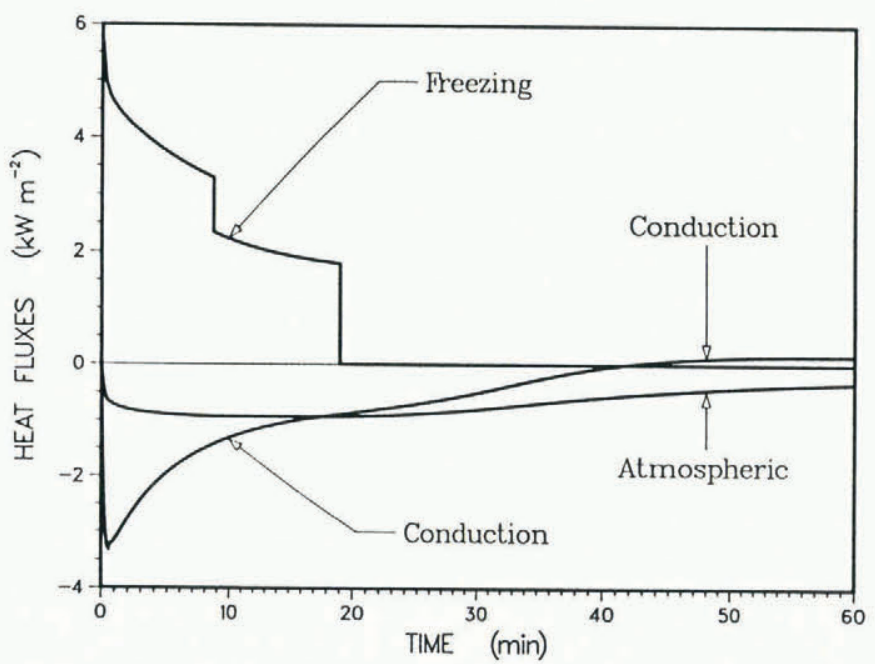

Fig. 4. Heat fluxes as a function of time. The conductive heat flux is between the two uppermost ice layers. The atmospheric flux is the sum of the radiative, convective, and evaporative or sublimative heat fluxes. The parameters are the same as in Figure 2.
The brine and ice thickness increase during the flooding (Fig. 5). After $15 \mathrm{~min}$, when the brine discharge stops, brine continues to freeze, and the water surface lifts slightly due to expansion of the underlying ice. The rate of growth of the ice interface in Figure 5 decreases with time. This is related to the heat-wave propagation inside the ice. The increasing temperature inside the ice (Fig. 3) means a decreasing temperature gradient at the ice surface. There is no change in the atmospheric fluxes while the liquid layer remains on the surface (Fig. 4), because the surface temperature is constant. Consequently, the decreasing heatconduction flux leads to a decrease in the ice-growth rate.

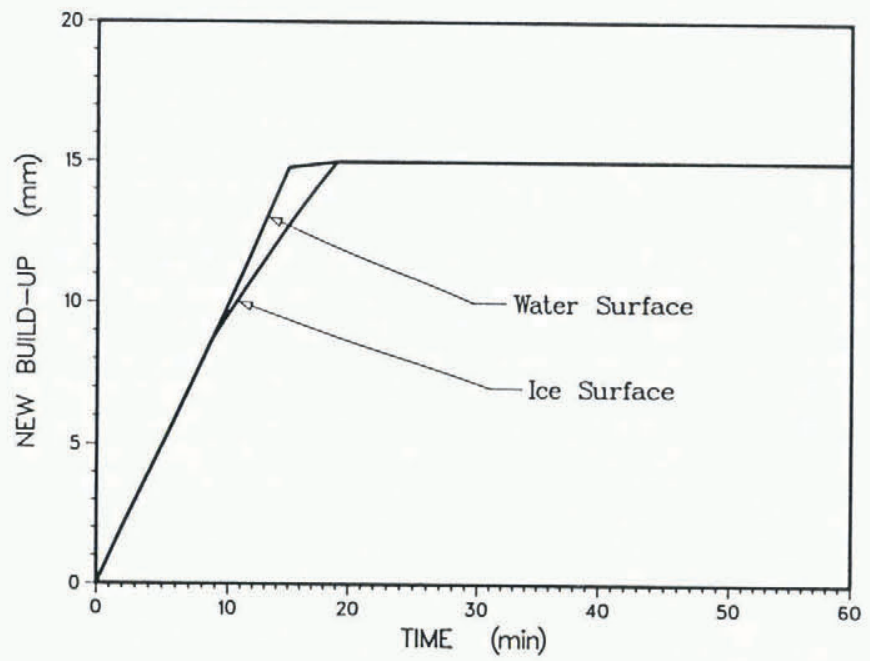

Fig. 5. Changes of the ice- and water-surface position with time. The parameters are the same as in Figure 2.

After approximately $19 \mathrm{~min}$, all the brine has "frozen" at $-3^{\circ} \mathrm{C}$, and the ice-surface temperature begins to decrease. The sign change of the conductive flux (Fig. 4) occurs at $41.5 \mathrm{~min}$. This is associated with the change in sign of the temperature gradient near the surface. The ice-surface temperature is no longer greater than the underlying ice-layer temperature, and the conductive heat flux, instead of tending to decrease the surface temperature, now tends to increase it. The heat wave propagates inside the ice. There is an increasing time delay to reach the maximum local ice temperature as one proceeds downwards (Figs 2 and 3). A damping of the amplitude of the heat wave with depth is also observed.

It is interesting to consider not only the changes of the heat fluxes with time (Fig. 4) but also the cumulative amounts of energy exchanged or released (Fig. 6). The icesurface temperature is always greater than the air

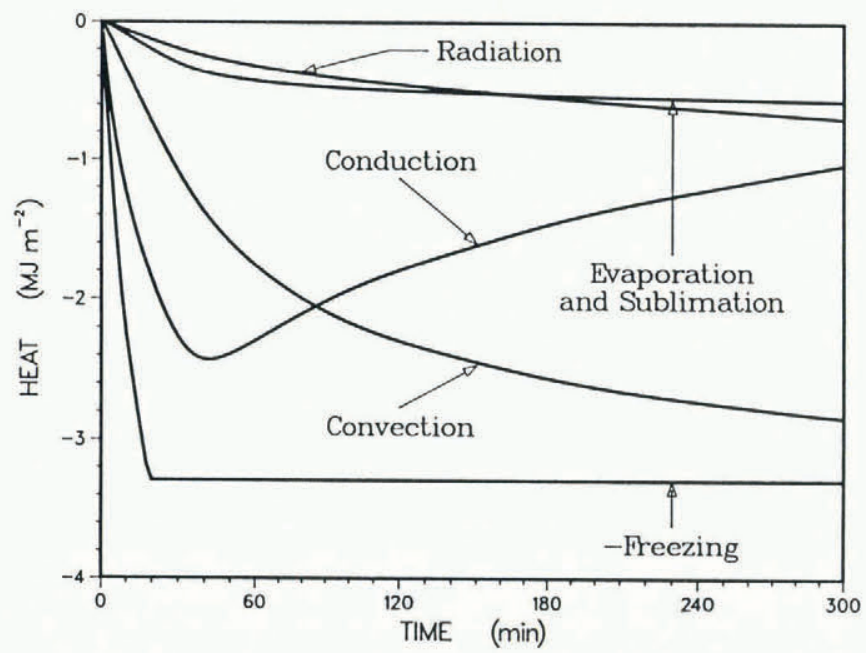

Fig. 6. Cumulative heat gains and losses by the surface layer as a function of time. For convenience, negative values of the heat of freezing are plotted. The parameters are the same as in Figure 2. 
temperature for these processes. Consequently, heat is lost by the ice surface due to radiation, convection, and sublimation or evaporation, and these heat fluxes are considered to be negative. After flooding, the decreasing temperature difference between the surface and the air causes a decrease in the atmospheric heat fluxes. The largest amount of energy is lost by convection. The magnitudes of the overall radiative, conductive, and sublimative heat losses are comparable. The energy released by freezing brine has a positive sign (Fig. 4), because it is a source in the ice-surface heat-energy balance. However, for convenience of plotting, negative values of the energy released due to freezing have been plotted in Figure 6 .

Heat conduction inside the ice may be divided into two terms. The first is related to the ice-temperature fluctuations caused by flooding. The second is associated with the average temperature gradient inside the ice resulting from the different average ice temperatures at the surface and at the bottom. The first heat flux is important over time intervals commensurate with the duration of the flooding. Heat is lost to the underlying ice rather rapidly over the first $40 \mathrm{~min}$. It is then subsequently regained more slowly from the underlying ice. After $5 \mathrm{~h}$, about half of the heat conducted into the ice is still there. However, over long time intervals (days) this fluctuating component can probably be neglected. On the other hand, the second heat flux starts to play an important role over very long time intervals. This flux is comparatively small but the total amount of energy over long time intervals could be significant.

In order to optimize the ice growth with repetitive flooding, the temperature in the upper part of the ice should be sufficiently low before the next flooding is applied. Consequently, the influence of wind speed, air temperature, and cloud cover on the maximum temperature in the five uppermost ice layers (approximately $10 \mathrm{~cm}$ ) has been examined. It is assumed that the duration of flooding is $15 \mathrm{~min}$ and that the thickness of the new ice build-up is $15 \mathrm{~mm}$. The method for calculating the initial conditions and the values of the remaining parameters have already been described at the beginning of this section.

The influence of wind speed, $U_{\mathrm{a}}=1,2, \ldots, 5 \mathrm{~m} \mathrm{~s}^{-1}$, on the maximum ice temperature, for a constant value of air temperature, $T_{3}=-30^{\circ} \mathrm{C}$, and cloudless skies, $n=0$, is presented in Figure 7. There is a rapid increase of the maximum temperature in this top $10 \mathrm{~cm}$ at the beginning of flooding for all cases. A brine layer on the surface exists not only during the flooding but also for some time after it stops. The time interval needed to completely "freeze" the newly flooded water is smaller for higher wind speeds. After all the water has "frozen", the maximum temperature decreases and the location of the temperature maximum moves downward in the ice (see Fig. 3). This is the reason for the abrupt changes in the slope of the maximum temperature curve. An increase in wind speed leads to a decrease of the time interval needed to reach a particular temperature in the uppermost ice layers.

The heat fluxes exchanged by convection and sublimation or evaporation are the main components of the heat lost to the atmosphere (Fig. 6). The radiative flux is comparatively small, and much of the heat which was initially conducted downward into the ice is subsequently released to the atmosphere. Since the convective fluxes are proportional to wind speed, changes in wind speed have a profound effect on the changes of the ice temperature close to the surface. For example, the maximum ice temperature drops to $-15^{\circ} \mathrm{C}$ after only $40 \mathrm{~min}$ at $5 \mathrm{~m} \mathrm{~s}^{-1}$. This requires about $90 \mathrm{~min}$ with a wind speed of $1 \mathrm{~m} \mathrm{~s}^{-1}$.

Similar calculations have been performed to investigate the influence of air temperature on the maximum ice temperature (Fig. 8). For these cases, the wind speed and cloud cover have the constant values $U_{\mathrm{a}}=4 \mathrm{~m} \mathrm{~s}^{-1}$ and $n=0$, respectively The air temperature varies over the range $T_{0}=-35^{\circ},-30^{\circ}, \ldots,-15^{\circ} \mathrm{C}$. When comparing cases with different air temperatures, one must remember that not only is the temperature different above the ice but also inside the ice, because we have assumed steady-state initial conditions. Consequently, when the temperature of the flooded ice surface is high, the air temperature influences not only the heat fluxes exchanged with the atmosphere by convection, evaporation/sublimation, and radiation but also

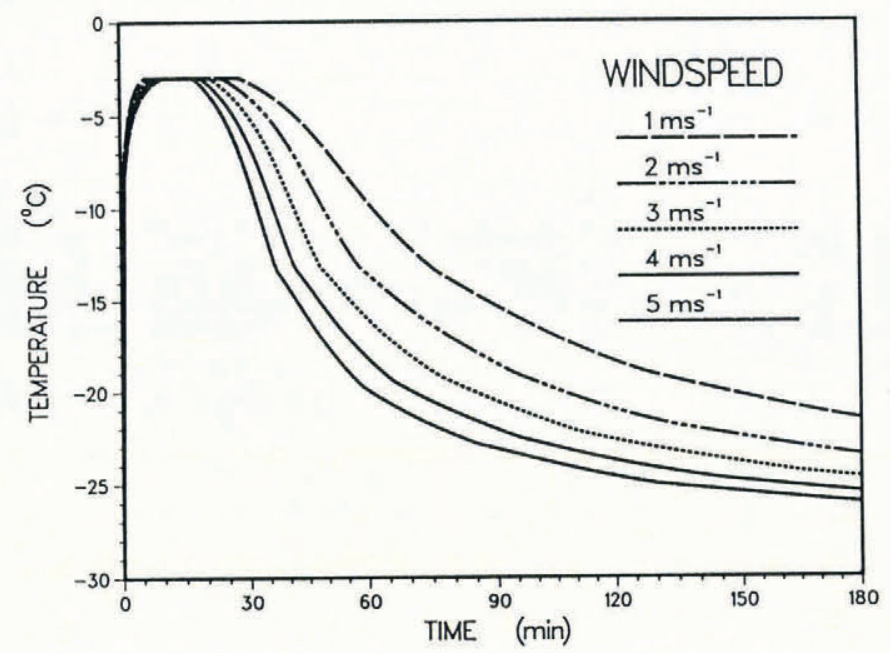

Fig. 7. Maximum temperature of the five uppermost ice layers (approximately $10 \mathrm{~cm}$ ) as a function of time for different wind speeds. Air temperature $-30^{\circ} \mathrm{C}$, cloudless skies, and new ice build-up of $15 \mathrm{~mm}$.

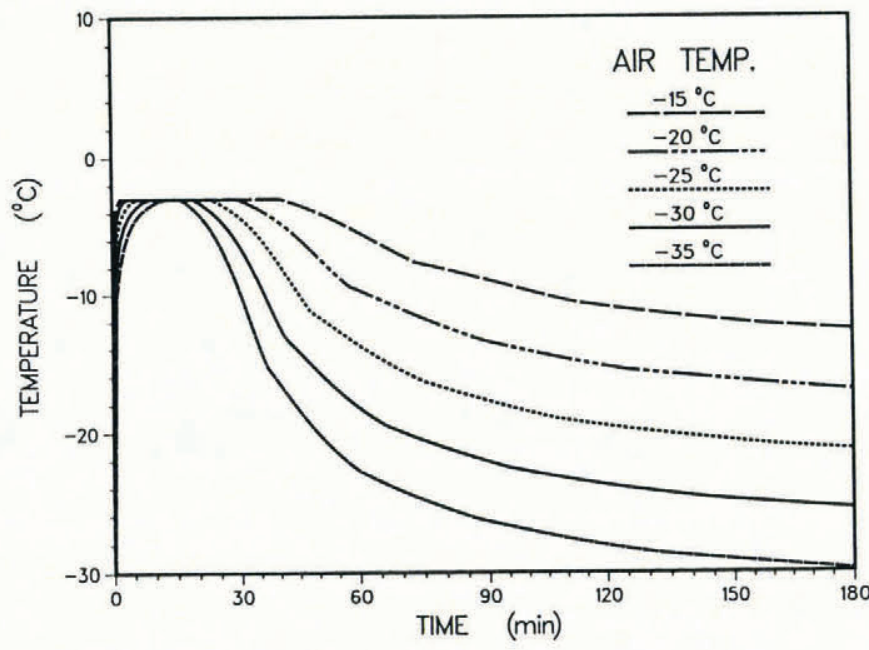

Fig. 8. Maximum temperature of the five uppermost ice layers (approximately $10 \mathrm{~cm}$ ) as a function of time for different air temperatures. Wind speed $4 \mathrm{~m} \mathrm{~s}^{-1}$, cloudless skies, and new ice build-up of $15 \mathrm{~mm}$.

the conductive heat flux into the ice interior. All of these heat fluxes are affected in different ways, which makes it difficult to establish simple quantitative conclusions. However, it is apparent from Figure 8 that the rate of decrease of the maximum ice temperature after all the brine has "frozen" increases with decreasing air temperature. For example, with $T_{2}=-35^{\circ} \mathrm{C}$, the maximum ice temperature reaches $-10^{\circ} \mathrm{C}$ after $30 \mathrm{~min}$. With $T_{\mathrm{a}}=-15^{\circ} \mathrm{C}$, almost $2 \mathrm{~h}$ are required.

The influence of cloud cover on the thermal processes in the ice has also been investigated. The values of wind speed and air temperature were kept constant at $4 \mathrm{~m} \mathrm{~s}^{-1}$ and $-30^{\circ} \mathrm{C}$, respectively (Fig. 9). An increasing cloud cover leads to an increase in the amount of incoming long-wave radiation. This additional source of energy is transformed into higher ice temperatures. However, the effect is a minor one in this case. The cloud-cover effect would be greater if the magnitude of the convective and sublimative heat fluxes were lower. This would happen with higher air temperatures and lower wind speeds.

The amount of brine supplied per flooding event also influences the temporal changes of the maximum ice temperature (Fig. 10). Constant values of air temperature $T_{\mathrm{a}}=-30^{\circ} \mathrm{C}$, wind speed $U_{\mathrm{a}}=4 \mathrm{~m} \mathrm{~s}^{-1}$, and cloud cover $n$ $=0$, have been considered. The same duration of flooding, $15 \mathrm{~min}$, has also been assumed for all cases. Consequently, by varying the water mass flux, different thicknesses of ice can be built up. Not surprisingly, an increase in the ice build-up thickness leads to an increase in the time needed to "freeze" all of the brine. It should be noted, however, 


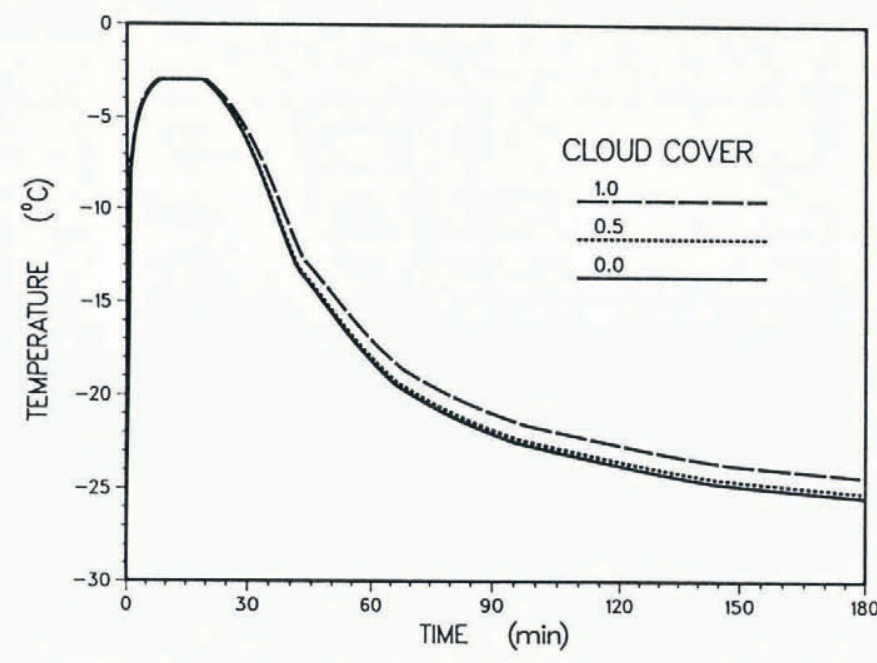

Fig. 9. Maximum temperature of the five uppermost ice layers (approximately $10 \mathrm{~cm}$ ) as a function of time for different cloud covers. Wind speed $4 \mathrm{~m} \mathrm{~s}^{-1}$, air temperature $-30^{\circ} \mathrm{C}$, and new ice build-up of $15 \mathrm{~mm}$.

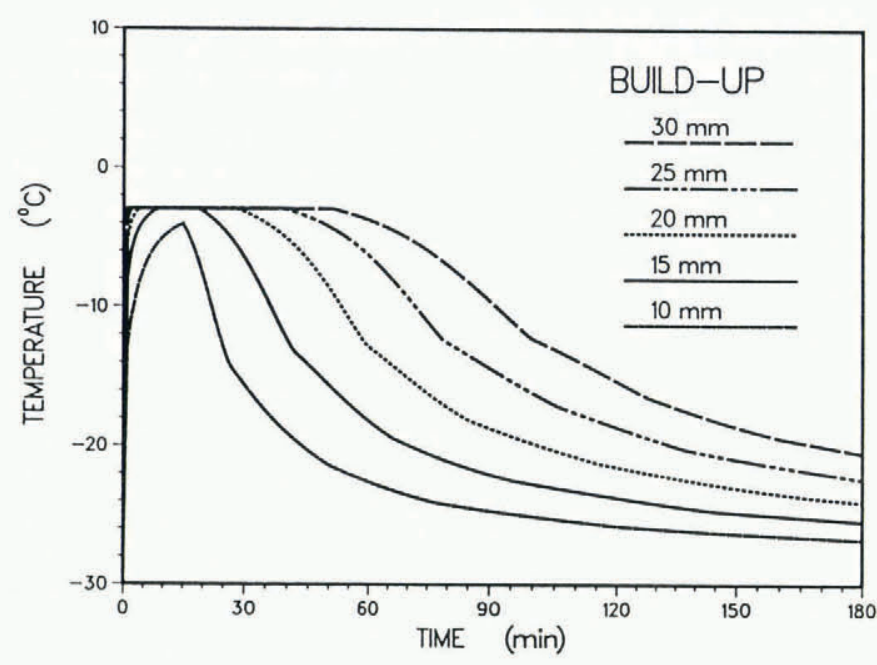

Fig. 10. Maximum temperature of the five uppermost ice layers (approximately $10 \mathrm{~cm}$ ) as a function of time for different values of the new ice build-up. Air temperature $-30^{\circ} \mathrm{C}$, wind speed $4 \mathrm{~m} \mathrm{~s}^{-1}$, cloudless skies.

that the time of freezing is not directly proportional to the ice build-up thickness. There is a limited amount of heat which can be quickly absorbed by the upper ice layers (Fig 4). Consequently, the total heat loss to the atmosphere must be bigger for the bigger ice build-up cases.

There is a critical value of the new ice build-up thickness for each set of external conditions. If the amount of pumped water is lower than this critical value, there is no water layer on the ice surface during the entire flooding period. In this case, the critical new ice build-up is about $10 \mathrm{~mm}$. For smaller values, the water freezes instantly during the entire flooding period. If one considers the time at which the maximum ice temperature descends to $-15^{\circ} \mathrm{C}$ to be the end of the flooding interval, and uses these times to work out an average growth rate, these rates vary from $21.4 \mathrm{~mm} / \mathrm{h}$ for the $10 \mathrm{~mm}$ build-up to $15.0 \mathrm{~mm} / \mathrm{h}$ for the $30 \mathrm{~mm}$ build-up.

\section{Building ice platforms by spraying}

Spraying of water into cold air can significantly decrease the time required on the surface to freeze the water. We explore this process as follows. Steady-state initial conditions have again been assumed. The values of the parameters are the same as in the previous section and the solutions have been obtained for $T_{\mathrm{a}}=-30^{\circ} \mathrm{C}, U_{\mathrm{a}}=4 \mathrm{~m} \mathrm{~s}^{-1}$, and $n=0$. The thickness of the new ice build-up is $15 \mathrm{~mm}$.
The influence of the spray heat-loss factor $C$ on the changes of the maximum temperature of the upper ice layers has been examined. When there is no spraying heat loss, $C=0$, and characteristic changes of the ice maximum temperature (Fig. 11) are observed. As the heat loss from the water droplets increases (increasing $C$ ), there is a decrease in the time interval during which the water layer

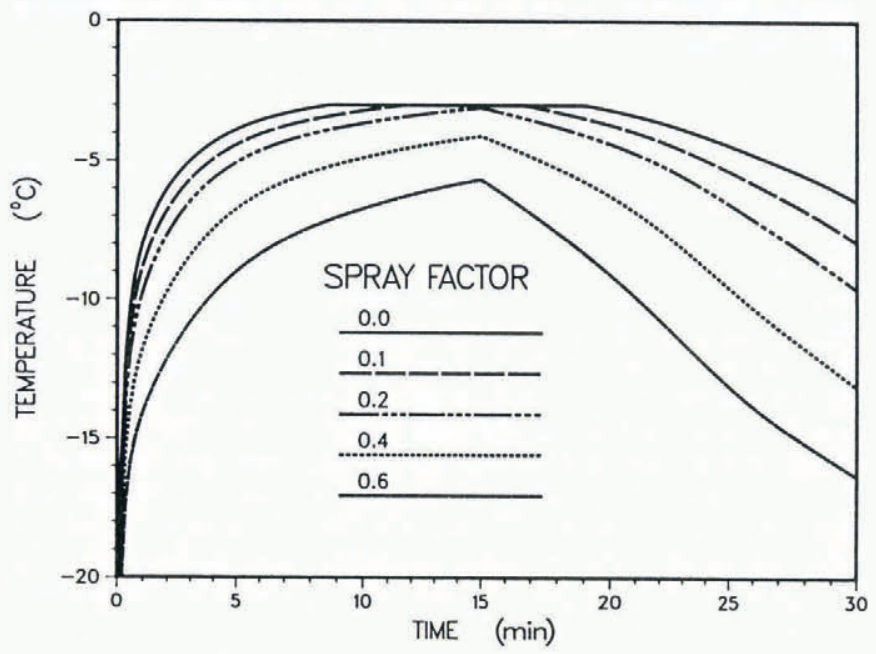

Fig. 11. Maximum temperature of the five uppermost ice layers (approximately $10 \mathrm{~cm}$ ) as a function of time for different values of the spray heat-loss factor. $C=0$ corresponds to flooding. Air temperature $-30^{\circ} \mathrm{C}$, wind speed $4 \mathrm{~m} \mathrm{~s}^{-1}$, cloudless skies, and new ice build-up of $15 \mathrm{~mm}$.

exists on the surface. The initial rate of rise of the maximum temperature also decreases. There is a critical value of the spray heat-loss factor for given atmospheric and spraying conditions. In the case considered, it is approximately 0.2 . If the spray heat-loss factor exceeds this critical value, there is no liquid water on the ice surface at any time. In these cases the ice-surface temperature increases slowly during the spraying without reaching the melting temperature. When the water delivery stops after $15 \mathrm{~min}$, there is an abrupt decrease in the ice-surface temperature.

When a water layer exists on the surface, the same rate of heat transfer prevails from the ice-surface layer whatever the spray heat-loss factor. This means that the freezing rate at the surface remains constant. However, during spraying, the rate of ice growth varies with the spray heat-loss factor, because different amounts of sprayed water freeze in the air before hitting the surface (assuming no drop supercools). This explains the abrupt changes in the rate of ice growth at the end of the spraying, $15 \mathrm{~min}$ after the beginning of the simulation. At this moment, the rate of ice growth is the same for all cases, if there is still a water layer on the surface. The general decrease of the rate of growth with time is caused by a decreasing gradient of temperature in the ice at the surface.

\section{Pulsed flooding and spraying}

In reality, flooding and spraying are applied not only once but in a repetitive, pulsed manner. After a period of flooding, there is a curing time required for the ice to freeze and to cool down before the next pulse may be applied. Although the solutions presented in the two previous sections, which represent only the first pulse, give some insight into the problem, they do not represent the oscillatory process. Subsequent pulses may be applied before reaching steady-state conditions. Consequently, in practical situations, the ice layer will have a higher average temperature than in the case of a single pulse. This means that less heat can be absorbed by the ice layer and the time of freezing will be longer for repetitive flooding or spraying.

In this section a pulsed water supply is considered. The solutions are obtained using the same procedures for calculating the boundary conditions as in the two previous 
sections. However, the initial conditions have been modified We wish to begin these simulations with initial conditions which are representative of a system which has been exposed to a series of flooding or spraying pulses. If only the surface temperature changes periodically, a dynamic steady state would be achieved by the system after some time. However, in the case of water delivery, the thickness of the ice increases with time. Consequently, a purely quasi-steady-state solution cannot be achieved for flooding or spraying. In order to overcome this problem, the following approach has been used to achieve appropriate initial conditions. Ice of constant thickness, $3 \mathrm{~m}$, is flooded periodically with "the same water". The ice which builds up during a given flooding event is removed at the beginning of the next flooding, restored to a temperature of $-1.8^{\circ} \mathrm{C}$, and delivered as liquid water again. Consequently, while this process is going on, the ice thickness remains constant in spite of flooding. After a sufficiently long time, dynamic steady-state oscillations of the temperature distribution inside the ice are achieved. This solution is not a function of the initial distribution of temperature. After several pulses, the system has reached a dynamic steady state. The solutions presented in this section were obtained using this approach.

The changes of the ice temperature close to the surface are shown in Figures 12 and 13. The following values of the parameters have been assumed: air temperature $T_{\text {a }}$ $=-30^{\circ} \mathrm{C}$, wind speed $U_{\mathrm{a}}=4 \mathrm{~m} \mathrm{~s}^{-1}$, clear-sky conditions

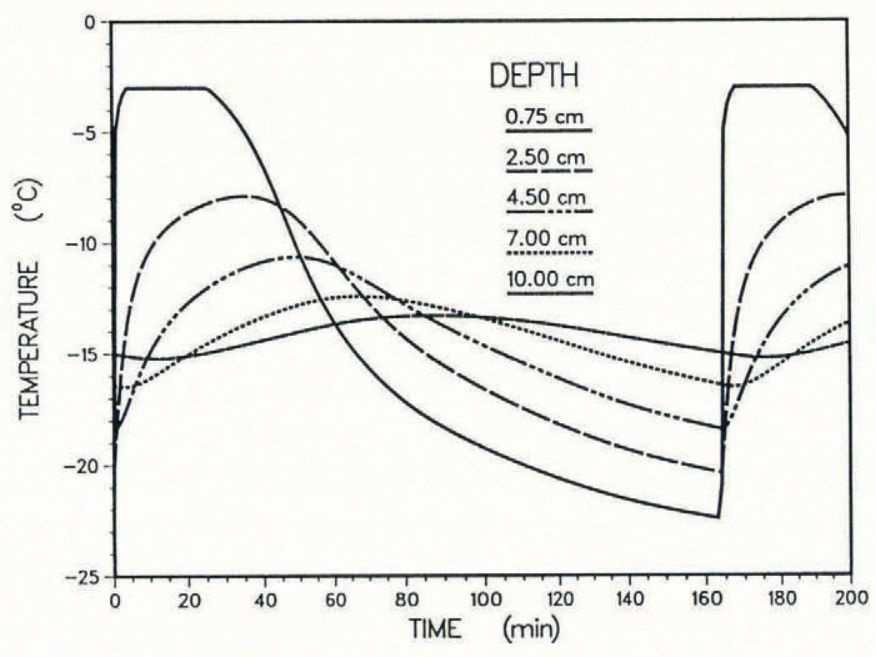

Fig. 12. Temperature of the five uppermost ice layers as a function of time for pulsed flooding. The depth is the value after the first flooding. Air temperature $-30^{\circ} \mathrm{C}$, wind speed $4 \mathrm{~m} \mathrm{~s}^{-1}$, cloudless skies, new ice build-up of $15 \mathrm{~mm}$. critical ice temperature $-15^{\circ} \mathrm{C}$.

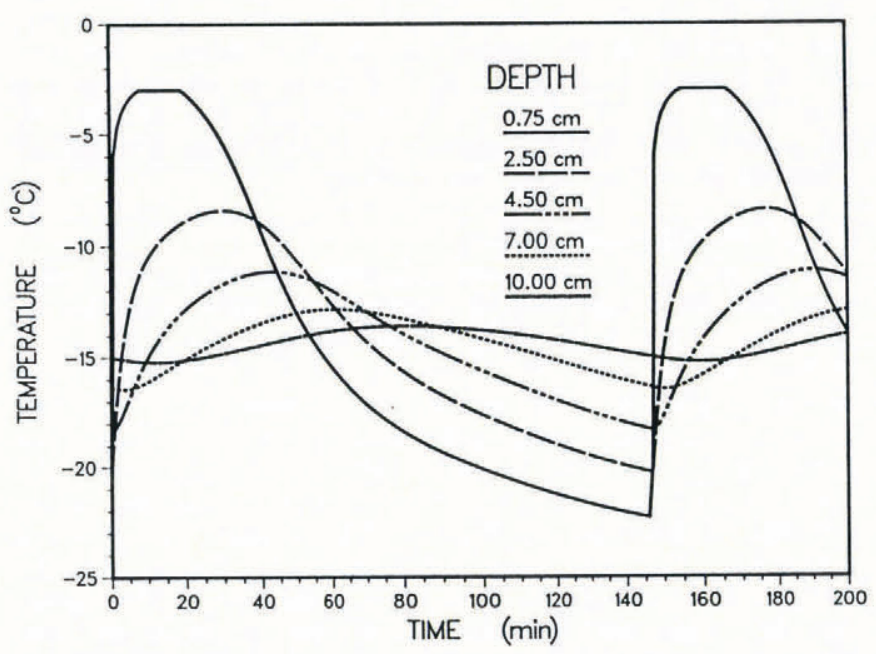

Fig. 13. Temperature of the five uppermost ice layers as a function of time for pulsed spraying. The spray heat-loss factor is 0.2. The remaining parameters are the same as in Figure 12. $n=0$, and the thickness of the new ice build-up pulse $15 \mathrm{~mm}$. The pulses are applied when the ice temperature in all five layers adjacent to the surface (the new layer plus the top $10 \mathrm{~cm}$ of existing ice) drops below $-15^{\circ} \mathrm{C}$. This temperature we have called the critical ice temperature. The calculations were done for two cases: flooding (Fig. 12) and spraying with a spray heat-loss factor $C=0.2$ (Fig. 13).

The quasi-steady-state solutions show the advantage of spraying. When water is flooded, $15 \mathrm{~mm}$ of ice is built up in $163 \mathrm{~min}$. If the water is sprayed with a spray heat-loss factor $C=0.2$, the period is reduced to $146 \mathrm{~min}$. Consequently, a $12 \%$ increase in the rate of ice growth is achieved by spraying (given the assumed spray heat-loss factor) for the same atmospheric conditions.

The rate of ice growth is a function of both the atmospheric and spraying parameters: the air temperature and wind speed, the cloud cover, the spray heat-loss factor, the water-supply interval, the new ice build-up per pulse, the total ice thickness, and the critical value of the ice temperature which determines the next pulse. Calculations have been done to determine the influence of some of these parameters on the rate of ice growth. Constant values of the following parameters have been assumed: cloudless skies, $n=0$, a water-supply interval of $15 \mathrm{~min}$, a new ice build-up per pulse of $15 \mathrm{~mm}$, a total ice thickness of $3 \mathrm{~m}$, and a critical ice temperature of $-15^{\circ} \mathrm{C}$.

The influence of the spray heat-loss factor and wind speed on the rate of ice growth is presented in Figure 14. The air temperature is $-30^{\circ} \mathrm{C}$. An increase in the spray heat-loss factor with a constant wind speed leads to an increase in the rate of ice growth and a decrease in the time interval during which a water layer exists on the ice surface. Any further increase in the spray heat-loss factor leads to disappearance of the water layer on the surface. An increase of the wind speed seems to have the same influence on the relative increase of the rate of ice growth, whatever the spray heat-loss factor.

The rate of ice growth as a function of the spray heat-loss factor and the air temperature for a constant wind speed, $U_{\mathrm{a}}=3 \mathrm{~m} \mathrm{~s}^{-1}$ is given in Figure 15. Over the range of air temperature and wind speed considered, the influence of these parameters is comparable. For example, for all values of the spray heat-loss factor, approximately the same rate of ice growth occurs for the two cases: $U_{\mathrm{a}}=3 \mathrm{~m} \mathrm{~s}^{-1}$, $T_{\mathrm{a}}=-40^{\circ} \mathrm{C}$, and $U_{\mathrm{a}}=5 \mathrm{~m} \mathrm{~s}^{-1}, T_{\mathrm{a}}=-30^{\circ} \mathrm{C}$.

Roughly speaking, the external heat transfer is proportional to the product of wind speed and the absolute value of the temperature in deg. Thus, increasing one and decreasing the other while keeping the product constant gives roughly the same rate of ice growth. Approximately, a wind-speed increase of $1 \mathrm{~m} \mathrm{~s}^{-1}$ has the same effect on the rate of ice growth as a drop in the air temperature of $5^{\circ} \mathrm{C}$.

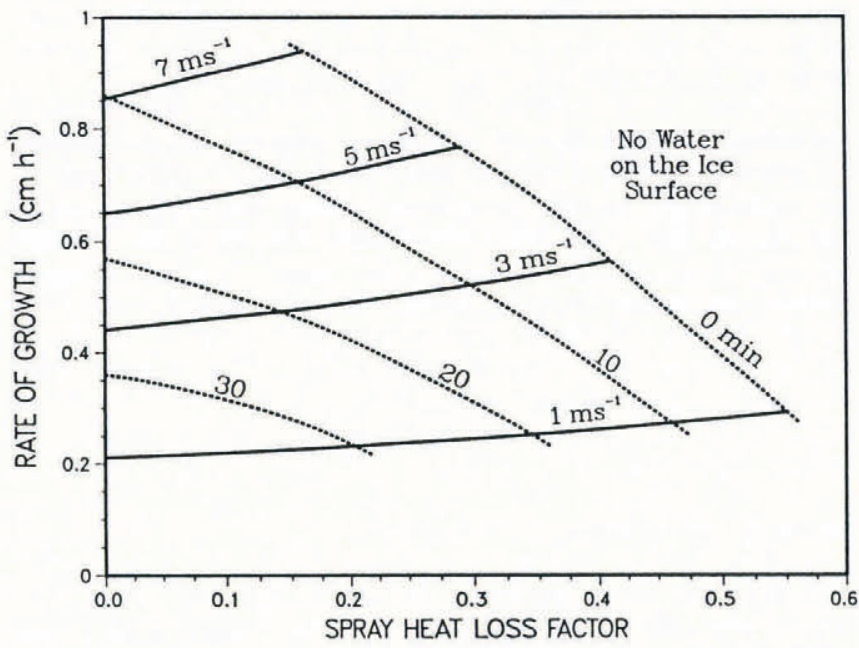

Fig. 14. Rate of ice growth as a function of spray heat-loss factor for different wind speeds. The isochrones are the duration of the water layer on the ice surface. Air temperature $-30^{\circ} \mathrm{C}$, cloudless skies, new ice build-up of $15 \mathrm{~mm}$, critical ice temperature $-15^{\circ} \mathrm{C}$. 


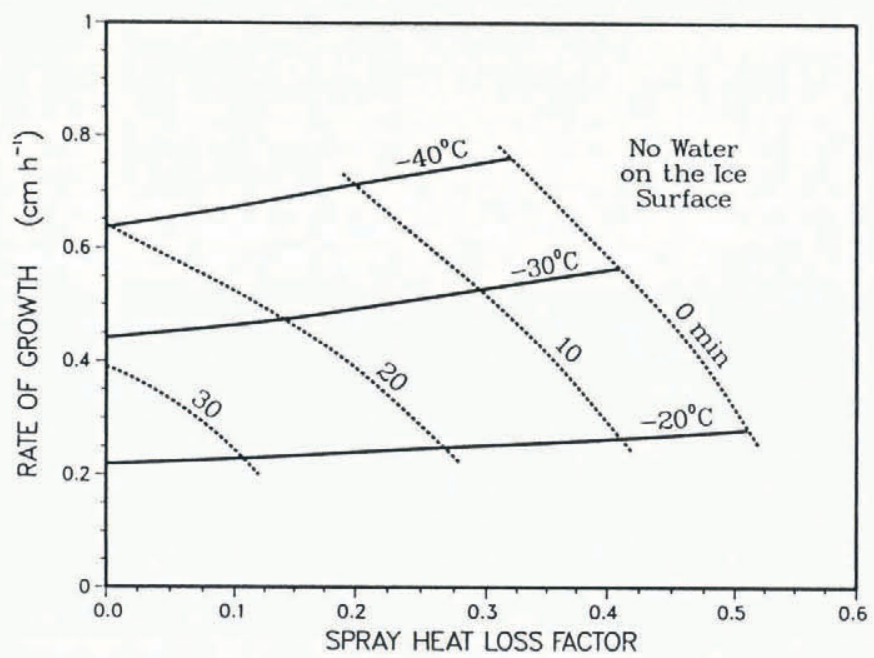

Fig. 15. Rate of ice growth as a function of spray heat-loss factor for different air temperatures. The isochrones are the duration of the water layer on the ice surface. Wind speed $3 \mathrm{~m} \mathrm{~s}^{-1}$, cloudless skies, new build-up of $15 \mathrm{~mm}$, critical ice temperature $-15^{\circ} \mathrm{C}$.

Conclusions from Figures 14 and 15 should be drawn carefully. These graphs have been obtained assuming that the spray heat-loss factor, wind speed, and air temperature are independent. In reality, the spray heat-loss factor depends on many factors, including both wind speed and air temperature. This means that if one wants to investigate the influence of wind speed or air temperature on the growth rate, one should not move along a line of constant spray heat-loss factor. If the wind speed increases or the air temperature decreases, the spray heat-loss factor will increase, thereby giving rise to higher values of the rate of ice growth.

Figures 14 and 15 have been obtained for constant values of the following parameters: critical ice temperature, cloud cover, water-supply interval, and new ice build-up thickness. It seems that the solution is most sensitive to the critical ice temperature which the ice must reach before the next flooding or spraying can be applied. This curing time can vary rapidly when temperature differences between the surface and the air are small. The influence of cloud cover could be important if the convective heat fluxes are small. When the air temperature is high and wind speed low, the changes of the radiative heat flux caused by changes in cloud cover are significant in comparison with the absolute value of the convective-heat flux. Conversely, when the air temperature is low or wind speed high, the cloud cover does not substantially influence the relations among the magnitudes of the heat fluxes.

The model can also be used to try to answer the following question: is it more efficient to build an ice platform by producing a few thick layers or many thin layers? Our experience with the model suggests that this problem may have different solutions for different atmospheric conditions (Szilder and Lozowski, 1988).

\section{Verification of the model}

There are insufficient published experimental data to permit extensive testing of the model. However, a partial verification has been performed by using data published by Nakawo (1980). His measurements of ice-temperature changes were made under repetitive flooding. The following parameters were also measured: $T_{\mathrm{a}}=-28^{\circ} \mathrm{C}, U_{\mathrm{a}}=3.9 \mathrm{~m} \mathrm{~s}^{-1}$, cloud cover $n=0.2$, eddy-transfer coefficient $B=0.004$, new ice-layer thickness $16 \pm 1 \mathrm{~mm}$, and duration of flooding $15 \mathrm{~min}$. Our model has been run for the same set of parameters and the results are shown in Figure 16. Because of the finite-difference nature of the model, temperatures of the ice obtained from the model are from slightly different depths than those of the measurements. However, a general qualitative agreement between them may be seen. There may be several reasons for the specific differences. First, it seems that Nakawo (1980) had some difficulties determining the precise depth of his measurements. The depth of one thermocouple changed from

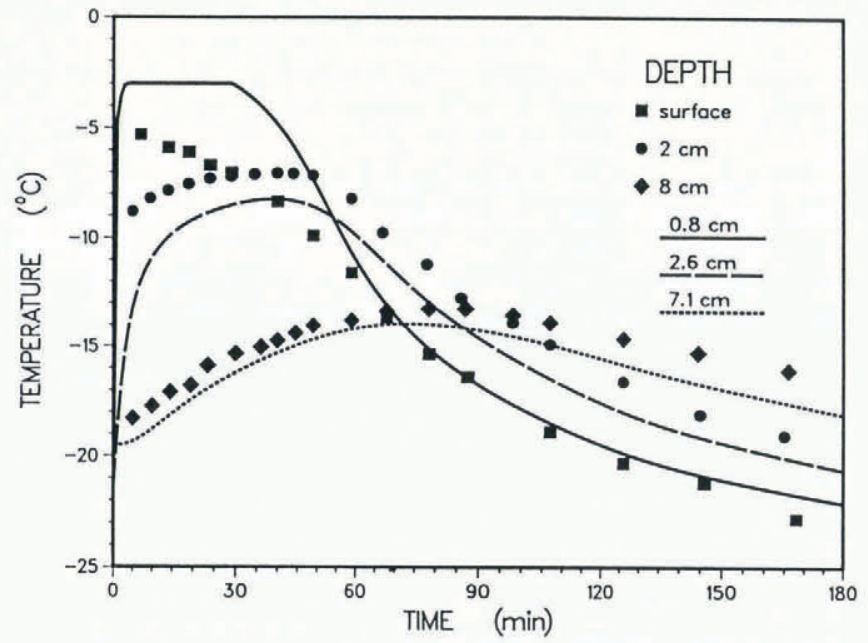

Fig. 16. Temperature changes at different levels in the ice after flooding. The model predictions are shown by the curves, Nakawo's experimental data by points. Air temperature $-28^{\circ} \mathrm{C}$, wind speed $3.9 \mathrm{~m} \mathrm{~s}^{-1}$, cloud cover 0.2 , eddy-transfer coefficient 0.004, and new ice build-up of $16 \mathrm{~mm}$. Depths are given after flooding.

0.8 to $2.0 \mathrm{~cm}$ and the second changed from 6.2 to $8.0 \mathrm{~cm}$ because of the flooding. The uncertainty about the depth of the measurements is related to an uncertainty in the thickness of the new ice build-up, and consequently in the amount of latent heat released during freezing.

The very rapid increase of the observed ice temperature at a final depth of $2 \mathrm{~cm}$ (initial depth of $0.8 \mathrm{~cm}$ ) suggests that water infiltration inside the ice layer may have occurred during flooding. Such a flow is not simulated by our model. There is also some uncertainty about the value of the eddy-transfer coefficient $\beta$. It should be noted that, even with constant wind speed, a change in the difference between the surface and the air temperature will have an influence on the actual eddy-exchange coefficient. The uncertainty about the appropriate values of the thermal properties of sea ice could also lead to differences between the measurements and the simulations.

The comparison between the measured average rate of ice growth and the model prediction is also satisfactory, in spite of a lack of detailed measurements of the atmospheric and flooding conditions. Such parameters as air temperature, wind speed, and ice critical temperature are essential for the thermodynamics of ice-platform construction.

Data presented by Pare and others (1987) were obtained during the construction of an ice platform by spraying. The rates of the ice growth predicted by our model are smaller than the values from these experiments. The observed data show significant growth even for high air temperatures, e.g. a rate of growth of $0.38 \mathrm{~cm} \mathrm{~h}^{-1}$ for $T_{\mathrm{a}}=-17^{\circ} \mathrm{C}$. This suggests that they are using a critical temperature which exceeds the value of $-15^{\circ} \mathrm{C}$ used in our model construction in Figures 14 and 15. As may be seen in Figures 7, 8, and 10, the value of the critical temperature has a significant influence on the pulsing period.

A general comparison with experimental data obtained for building ice platforms by flooding has also been performed. Unfortunately, insufficient meteorological data have been given in these studies to permit a detailed comparison with our model. Dykins (1963) claimed a value of $0.23 \mathrm{~cm} \mathrm{~h}^{-1}$ if the air temperature lies below $-23^{\circ} \mathrm{C}$. He spoke of applying $10 \mathrm{~cm}$ of water every $40-48 \mathrm{~h}$. Baudais and others (1974) gave a rate of ice growth of $0.29 \mathrm{~cm} \mathrm{~h}^{-1}$ for a variable temperature, varying from $-18^{\circ}$ to $-45^{\circ} \mathrm{C}$ and averaging $-34^{\circ} \mathrm{C}$. These values fall within the general range of ice-growth rates predicted by our model.

\section{CONCLUSIONS}

Our new time-dependent model for simulating the construction of artificial ice platforms appears to give results which are consistent with the limited published experimental data. The mathematical description of the 
model is solved using ACSL. The model can simulate the influence of atmospheric conditions on the thermodynamic processes in the ice. An increase in the wind speed, or a decrease in the air temperature or cloudiness, will cause an increase in the heat loss to the atmosphere and consequently, an increase in the rate of ice growth. The time variation of the heat conduction inside the ice also has an influence on the ice build-up process. At the beginning of a flooding or spraying cycle the ice is a heat sink, but later, as the surface temperature decreases, the ice becomes a heat source.

Experience with the model suggests several possible methods for increasing the rate of ice growth under particular atmospheric conditions. Spraying is one possibility. An increase in the spray heat-loss factor leads to an increase in the rate of ice growth. This relation is different for different wind speeds and air temperature. However, the relative increase of the rate of ice growth as a function of the spray heat-loss factor is approximately the same, as the wind-speed increase from 1 to $5 \mathrm{~m} \mathrm{~s}^{-1}$, or as the temperature decrease from $-20^{\circ}$ to $-40^{\circ} \mathrm{C}$.

One could also attempt to have an influence on the stability of the air and, hence, on the convective and evaporative heat fluxes by changing the wind speed, the difference between the surface and the air temperature, or the surface roughness. Increasing the ventilation with fans is a possibility but it may not be practical. Nor is it practical to maximize the air-surface temperature difference by keeping the surface wet at all times, since time must be allowed for ice solidification and surface cooling. The surface roughness could be increased artificially by erecting an array of fences over the flooding area. However, one should bear in mind that such an obstruction could decrease the wind speed substantially, thereby offsetting the advantage of increased surface roughness.

A substantial increase in the ice-growth rate can be achieved by allowing even a small increase in the critical ice temperature. However, the critical ice temperature cannot be too high or the quality of the ice may be compromised. Further research is therefore needed into the relationship between the critical ice temperature used to determine the flooding repetition frequency and the mechanical properties of the ice which results.

The model has been verified using a very limited set of published experimental and field data. Because of this, we cannot draw firm conclusions as to the validity of the model. However, it seems to be consistent with the available data. Our model has many advantages over existing models. The model is time-dependent, the changes of the icesurface and internal temperatures are outputs of the model, the model describes both flooding and spraying processes, and it allows a consideration of continuous changes in the atmospheric conditions.

There is a need, however, for more experimental data on the relationship between atmospheric conditions and ice thermodynamics and growth. Such data would permit more precise verification of the model. The influence of the ice temperature and ice salinity on its mechanical properties should also be established in order to estimate an optimum value of the critical temperature. Further research should also include an investigation of the influence of an artificial increase in surface roughness on the stability of the air and the wind speed, and, consequently, on the convective, evaporative, and sublimative heat fluxes.

\section{REFERENCES}

Baudais, D.J., D.M. Masterson, and J.S. Watts. 1974. A system for offshore drilling in the Arctic Islands. J. Can. Pet. Technol., 13(3), 15-26.

Brutsaert, W. 1982. Evaporation into the atmosphere. Dordrecht, etc., D. Reidel Publishing Company.

Budyko, M.I. 1974. Climate and life. New York, Academic Press.

Dykins, J.E. 1963. Construction of sea ice platforms. In Kingery, W.D., ed. Ice and snow; properties, processes, and applications. Cambridge, MA, M.I.T. Press, 289-301.

Eckert, E.R.G. and R.M. Drake. 1972. Analysis of heat and mass transfer. New York, McGraw-Hill Book Company.

Gebhart, B. 1971. Heat transfer. New York, McGraw-Hill Book Company.

Idso, S.B. and R.D. Jackson. 1969. Thermal radiation from the atmosphere. J. Geophys. Res., 74(23), 5397-5403.

Kemp, T.S., R.J. Foster, and G.S. Stevens. In press. Construction and performance of the Kadluk 0-07 sprayed ice pad. In POAC 87; the 9th International Conference on Port and Ocean Engineering under Arctic Conditions, August 1987, Fairbanks, U.S.A.

Lowe, P.R. 1977. An approximating polynomial for the computation of saturation vapor pressure. J. Appl. Meteorol., 16, 100-103.

Lunardini, V.J. 1981. Heat transfer in cold climates. New York, Van Nostrand Reinhold Company.

Masterson, D.M., K.G. Anderson, and A.G. Strandberg. 1979. Strain measurements in floating ice platforms and their application to platform design. Can. J. Civ. Eng., 6(3), 394-405.

Mitchell and Gauthier Associates Inc. 1981. Advanced continuous simulation language; user guide and reference manual. Concord, MA, Mitchell and Gauthier Associates.

Nakawo, M. 1980. Heat exchange at surface of a built-up ice platform during construction. Cold Reg. Sci. Technol., 3(4), 323-333.

Nakawo, M. 1983. Criteria for constructing ice platforms in relation to meteorological variables. Cold Reg. Sci. Technol., 6(3), 231-240.

Pare, A., L.E. Carlson, M. Bourns, and N. Karim. 1987. The use of an additive in sprayed sea water to accelerate ice structure construction. In Cheng, K.C., V.J. Lunardini, and N. Seki, eds. Proceedings of the 1987 International Symposium on Cold Regions Heat Transfer ... Edmonton, Alberta, Canada, June 4-7, 1987. New York, American Society of Mechanical Engineers, 123-129.

Sellers, W.D. 1965. Physical climatology. Chicago, University of Chicago Press.

Serreze, M.C. and R.S. Bradley. 1987. Radiation and cloud observations on a High Arctic plateau ice cap. J. Glaciol., 33(114), 162-168.

Szilder, K. and E.P. Lozowski. 1988. Some results from a time-dependent thermodynamic model of the construction of floating ice platforms. In Jacobs, H.R., ed. $A S M E$ Proceedings of the 1988 National Heat Transfer Conference, Vol. 3. Houston, TX, 225-233.

Yen, Y.-C. 1981. Review of thermal properties of snow, ice and sea ice. CRREL Rep. 81-10.

Zarling, J.P. 1980. Heat and mass transfer from freely falling drops at low temperatures. CRREL Rep. 80-18. 